\title{
"DE REDUCTIONE ARTIUM AD THEOLOGIAM" DE SÃO BOAVENTURA (II).
}

\section{(Continuação) .}

\section{NACHMAN FALBEL}

do Departamento de História da Faculdade de Filosofia, Letras e Ciências Humanas da Universidade de São Paulo.

\section{III}

\section{LISTA DAS OBRAS DE SÄO BOAVENTURA.}

(Segundo a edição dos frades de Quaracchi; Doctores Seraphici $S$. Bonaventurae S. R. E. Episcopi Cardinalis Opera omnia, 10 vol. in - fol. Ad Claras Aquas (Quaracchi) prope Florentiam, ex typographia Collegii, S. Bonaventurae, 1882-1902).

Colocamos as datas ao lado das obras segundo E. Gilson ( $L a$ philosophie de $S$. Bonaventure) e Frei Leon Amorós, O. F. M. (Introdução a edição das obras de São Boaventura pela B. A. C., Madrid, tomo I). Nem sempre as datas dêstes autores coincidem, portanto colocamos as duas especificando a de Gílson com a letra $G$ e a de Amorós com a letra $A$. Acrescentamos, também, os tomos e as páginas em que aparecem na edição de Quaracchi.

I. - OBRAS FILOSÓFICAS E TEOLÓGICAS.

1. - Commentarii in quatuor libri Sententiarum Petri Lombardi, T. I-IV, G (1248 - 1255); A (1250 1252).

2. - Quastiones disputatae VIII de mysterio Trinitatis, T. V, 45-115; $A$ (1253-1254).

3. - Quaestiones disputatae VII de scientia Christi, T. V, 3-43; Ano: $A$ (1254-1255).

4. - Quaestiones disputatae IV de perfectione evangelica, T. V, 117-198; Ano: $A$ (1255-1256). 
5. - Breviloquium, T. V, 201-291; $G$ e $A$ (antes de 1257).

6. - Itinerarium mentis in Deum, T. V, 295-313; $G$ e $A$ (outubro de 1259).

7. - De reductione artium ad Theologiam, T. V, 319-325; (1251?).

8. - Collationes in Hexaemeron sive illuminationes Ecclesiae, T. V, 327-454; $G$ e $A$ (1273).

9. - Collationes septem de donis Spiritus Sancti, T. V, 457-503; $A$ (25 de fevereiro -7 abril 1268).

10. - Collationes de decem praeceptis, T. V, 507-531; G (1267 ou 1268); $A$ (fevereiro - abril de 1267).

11. - Sermones selecti de rebus theologicis, T. V, 535-538.

12. - De plantatione Paradisi (Gilson omite esta obra em sua lista), T. V, 574-579.

\section{II. - OBRAS EXEGÉTICAS.}

1. - Commentarius in librum Ecclesiastes, T. VI, 3-99.

2. - Commentarius in librum Sapientiae, T. VI, 107-233.

3. - Commentarius in Evangelium Sancti Ioannis, T. VI, 239-530.

4. - Collationes in Evangelium Sancti Ioannis, T. VI, 535-634.

5. - Commentarius in Evangelium Sancti Lucae, T. VII 3-604; $G$ (1248); $A$ (1248-1250).

III. - OBRAS ASCÉTICAS E MISTICAS.

1. - De triplici via, T. VII, 3-18.

2. - Soliloquium, T. VIII, 28-67.

3. - Lignum vitae, T. VII, 68-86.

4. - De quinque festivitatibus pueri lesu, T. VIII, 88-95.

5. - Tractatus de praeparatione ad missam, T. VIII, 99-106.

6. - De perfectione vitae ad sorores, T. VIII, 107-127; $A$ (1270).

7. - De regimine aminae, T. VIII, 128-130.

8. - De sex alis Seraphim, T. VIII, 131-151.

9. - Officium de passione Domini, T. VIII, 152-158.

10. - Vitis mystica seu tractatus de passione Domini, T. VIII, 159-189.

\section{IV. - OBRAS REFERENTES A ORDEM FRANCISCANA.}

1. - Apologia pauperum contra caluminiatorem, T. VIII, 234-330; $G$ e $A$ (1269). 
2. - Epistola de tribus quaestionibus ad magistrum innominatum, T. VIII, 331-336.

3. - Determinationes quaestionum circa regulam fratrum minorum, T. VIII, 337-374.

4. - Quare Fratres minores praedicent et confessiones audiant, T. VIII, 375-381.

5. - Epistola de sandalis Apostolorum, T. VIII, 386-390.

6. - Expositio super regulam Fratrum Minorum, T. VIII, 391-437.

7. - Sermo super regulam Fratrum minorum, T. VIII, 438-448.

8. - Constitutiones generales Narbonenses, T. VIII, 449-467; $G$ e $A$ (10 de junho de 1260).

9. - Epistolae varie.

a). - Epistola ad Ministros provinciales et Custodes (23 de abril 1257); T. VIII, 468-470.

b). - Epistola ad omnes Ordinis Ministros provinciales (Paris 16 de maio 1266); T. VIII, 470-471.

c). - Epistola ad Fratres Custodem et Guardianum (Pisa, 16 de maio de 1271); T. VIII, 471.

d). - Epistola ad Fratrem Laurentium (Assis, 29 de setembro de 1263); T. VIII, $471 \mathrm{~s}$.

e). - Epistola ad Fratres universos (Paris, 27 de maio de 1266); T. VIII, $472 \mathrm{x}$.

f). - Epistola ad abbatem Sanctae Mariae Blesensis (Paris, 20 de maio, 1273); T. VIII, $473 \mathrm{~s}$.

g). - Epistola ad abbatisam et Sorores Sanctae Clara Monasterii de Amisio (Alverna, outubro de 1259); T. VIII, $473 \mathrm{~s}$.

h). - Epistola ad decanum et Capitulum ecclesiae Sarburgensis (Lyon, 23 de janeiro de 1265). $O$ texto desta epístola não foi encontrado ainda, cf. $\mathrm{X}, 57$.

i). - Epistola confraternitates ad congregationem $B$. $M$. Virginis in civitate Brixiensi (1274), T. $\mathrm{X}, 63$.

10. - Regula novitionum, T. VIII, 475-490.

11. - Epistola continens viginti quinque memoralia, $\mathrm{T}$. VIII, 491-498.

12. - Epistola de imitatione Christi, T. VIII, 499-503.

13. - Legenda sancti Francisci (Assis, 1261), T. VIII, 504564. 


$$
\begin{aligned}
& -62- \\
& \text { 14. - Legenda minor sancti Francisci, T. VIII, 564-579. } \\
& \text { V. - SERMÕES. } \\
& \text { 1. - Sermones de tempore (330 sermōes correspondentes } \\
& \text { aos tempos do ano litúrgico), T. IX, 23-461. } \\
& \text { 2. - Sermones de Sanctis (68 sermões), T. IX, 463-631. } \\
& \text { 3. - Sermones de B. Virgine Maria (24 sermöes), T. IX, } \\
& \text { 633-721. . } \\
& \text { 4. - Sermones de diversis (5 sermões), T. IX, 723-731. }
\end{aligned}
$$

Após a edição famosa de Quaracchi, encontraram outros escritos de São Boaventura, cuja edição sistemática ainda não foi feita. Êstes manuscritos se encontram espalhados em algumas bibliotecas européias e foram identificados por diversos especialistas.

\section{IV}

A ESCOLA FRANCISCANA E O CARÁTER DE SUA FILOSOFIA.

a). - A fonte Agostiniana.

"Santo Agostinho, o mais filósofo dentre os Santos Padres e o teólogo mais ifluente da Igreja, é o verdadeiro criador da teologia ocidental, o que deu vida a uma série de ramos ou disciplinas da ciência sagrada, como a homilética e a hermenêutica em seus livros De doctrina Chriștiana, e a catequese, no tratado De catechizandìs rudibus",

assim se expressa Martin Grabmann (45), o grande historiador da filosofia medieval. Sem dúvida, a afirmação do estudioso mencionado não peca por exagêro e expressa em têrmos verdadeiros o papel que o Santo desempenhou no pensamento ocidental.

Até a introdução de Aristóteles, no século XII, com as traduções árabes e hebréias, o agostinismo determinou os cânones do pensamento expeculativo teológico. Suas idéias àcêrca das relações entre a autoridade e a razão, entre a fé e a ciência, estabeleceram o princípio orientador da especulação teológica dos séculos posteriores na fórmula repetida fides quaerens intellectum.

Em sua obra encontramos os textos básicos que serviram de fundamentos para a criação de uma teologia no Ocidente cristão -

45). - Citado na Introdução às obras de Santo Agostinho, tomo I, B. A. C., Madrid, 1957, p. 88. 
entre êles, o De Trinitate e o De Civitate Dei, extendendo-se sua influência a filosofia dogmática, a ética, bem como as doutrinas políticas da Igreja (46).

Chegando ao Cristianismo, depois de passar por um longo processo de conversão, onde o debate interno o levava às mais diversas tendências, acabou fixando-se na fé cristã, elaborando passo a passo a sua crença, com um esfôrço intelectual profundo e um espírito de investigação raro. Do racionalismo maniqueu e dualista chega à desilusão total para reconstruir-se na fé. No opúsculo De utilitate credendi êle descreve o itinerário de sua alma em busca da verdade, que sempre ambicionou, e os vagueios de sua mente; nas Confissóes o mesmo itinerário da alma vivida em angústia existencial é redimida pelo Cristianismo finalmente encontrado. Daí para Santo Agostinho a função da filosofia, para o cristão, ser a procura do conhecimento de Deus, orientada pela revelação escrita, através de sua imagem na alma. E a alma é encarada como o que dá ao corpo seu sêr específico de organismo humano. Daí ser ela, a alma, preeminente e superior ontològicamente ao corpo.

"A alma é coisa espiritual, incorpórea e próxima a substância de Deus - res spiritualis est, res incorporea est, vicina est substantiae Dei"' (47).

Por outro lado, o princípio de todo momento e investigação religiosa é a inquietude ou o desejo de salvar a alma. O crêr na sua imortalidade é verdadeiramente o que move o homo religiosus.

A inquietude espiritual ou o desêjo de salvar a alma é o princípio de tôda investigação religiosa (48). E, apesar de haver um égo, sujeito à existência, ao conhecimento, em nenhum dêstes aspectos é o ego auto-suficiente ou independente; êste ego não pode manter seu próprio sêr, produzir seu próprio conhecimento ou satisfazer seus próprios desejos. A fé na Providência Divina, sem a qual não há religião, é um outro princípio ou postulado básico (49). A aceitação da Providência se apoia, também, sôbre um sistema de certezas racionais, que dão testemunho do Deus Criador e Ordenador do mundo; a voz da "Natureza", ou a ordem universal; a voz da "consciência", que nos impele a servir a um Sêr superior, causa de tudo quanto existe; e a voz do "gênero humano", cujo sentir comum dos melhores homens,

(46). - Landry (Bernard), L'idée de chrétienté chez les scolastiques du XIIIe siècle. Presses Universitaircs de France. Paris. 1929, pp. 3-22.

(47). - De immort. animae, XV, 24.

(48). - De util. cred., VII, 14 (PL 42, 75).

(49). - Ibid., XVI, 34 (PL 42, 89). 
pela sua vida e exemplo nos estimulam ao culto religioso (50). Santo Agostinho crê que êle aprendeu dos Platônicos a encontrar em Deus

"o autor de tôdas as existências, o iluminador de tôda a verdade, o doador de tôda a beatitude" (51).

Quanto à investigação da verdade e à esperança de encontrá-la afirma que

"é impossível pela disposição da providência divina, que as almas religiosas que piamente, casta e diligentemente se buscam a si mesmas e a seu Deus, isto é, a verdade, que lhes faltem os meios suficientes para consegui-lo" (52).

E' patente a influência de Platão no pensamento de Santo Agostinho, e o filósofo da Academia perpetuou sua filosofia na Idade Média graças à interpretação efetuada pelo mais brilhante gênio da Igreja ocidental. Ele mesmo chega a afirmar no De civitate Dei;

“... isti (platonici) Deo cognito reppererunt ubi esset et causa constitutae universitatis et lux percipiendae veritatis et fons bibendae felicitatis. Sive ergo isti Platonici sive quicumque alii quarumlibet gentium philosophi de Deo ista sentiunt, nobiscum sentiunt" (53).

Mais adiante dirá que Platão tinha lido as Escrituras Sagradas para se inspirar em uma concepção do divino tão próximo ao Cristianismo.

Portanto esta filosofia, sob o impulso de Platão, aspira ao mundo inteligível, ou o reino das idéias divinas, isto é, a uma explicação racional e última do mundo por suas razões causais ou exemplares, que residem na mente do Criador. Este mundo inteligivel de Platão é para Santo Agostinho o Verbum Patris, a Forma formarum, a intelligibilis lux, com que iluminam tôdas as coisas.

O pensamento platônico,

"quod in philosophia purgatissimum est et lucidissimum" (54

também é revivido em seu discípulo afastado em tempo mas importante na explicação do agostinismo, Plotino,

(50). - De util. cred. XVI, 34 (PL 42, 89).

(51). - De quant. animae, XIV, 24 (PL 32, 1049).

(52). - De quant. animae, XIV, 24.

(53). - De civit. Dei., X, 3, 1.

(54). - Contra acadêmicos, III, XVIII, 41. 


\begin{abstract}
"filósofo platônico que foi julgado tão semelhante a seu mestre, que se creria que tinham vivido juntos, mas devido à grande distâncià de tempo que os sspara, melhor seria dizer que neste reviveu aquêle" (55).
\end{abstract}

O marcado acênto platônico na filosofia agostiniana ainda não é o suficiente para impedí-lo de afirmar a concordia ou a harmonia de Aristóteles e Platĩo (no extrito campo da filosofia), que constitui para êle a verissima philosophiae disciplina. Porém a razão, ratio subtilissima, dos filósofos não é suficiente para elevar a humanidade e arrancá-la das trevas. Para tanto, se faz necessária a revelação. $O$ platonismo, ou em sua essência mais valiosa, a doutrina das idéias, é um impulso dialético que leva a Cristo, como razão exemplar do mundo e o sol eterno das inteligências criadas (56).

Dotado de uma profunda espiritualidade, espiritualidade vivida em uma experiência quase angustiante, Santo Agestinho em sua filosofia conseguiu transmitir a herança do pensamento grego, bàsicamente em sua linha platônica, e modelá-la dentro do quadro da religiosidade cristã (57). Sua filosofia se resume na fórmula tríplice de ordem, desordem, graça: criação, caída, redenção, que na verdade se transmitirá ao mundo medieval e traçará uma ponte de contáto com seus discípulos da escola franciscana a partir de Alexandre de Hales e atingindo uma de suas máximas expressões em São Boaventura. Filosofia platônica e exemplarísta, eminentemente antropológica (58), porque estuda o homem em seu sêr concreto, é o caráter marcante do pensamento do bispo de Hipona e também o será de seus herdeiros.

b). - Avicebron e sua influência na Escola Franciscana e na filosofia do século XIII.

Guilherme de Auvergne (59) que foi mestre-regente em teologia de 1222 a 1228 , depois bispo de Paris de 1228 até sua morte em 30 de maio de 1249, se refere a ibn Gabirol como unicus omnium philosophantium nobilissimus (60). Até a descoberta do manuscrito he-

(55). - Ibid., III, XVIII, 41, “... Plotino, qui platonicus philosophus ita eius similis iudicatus est, simil cos viscisse, tantum autem interest temporis ut in hoc ille revixisse putandus sit.

(56). - Obras de San Agustin, T. III, B. A. C., 1963, p. 56.

(57): - Gilson (E.), L'Esprit de la philosophie médiévale. Lib. phil. J. Vrin. Paris. 1944, p. 176. "Sans le Phédon,. le de Immortalitate animae de Saint Agustin n'existerait certainement pas".

(58). - Obras de San Agustin, T. III, B. A. C., 1963, p. 57; Ibid. p. 57.

(59). - Segundo M. de Wulf, Histoire de la philosophie médiévale, t. II, 1936, pp. 64-75, "un des esprits les plus originaux de la première moitiè du siècle... Guillaume est le premier grand philosophe du XIIIe siècle".

(60). - Fraile (G.), História de la Filosofia, II, B. A. C. Madrid. 1966, p. 560; Jewish Encyclopedia, New York-London. 1906, vol. VI. 
bráico do Makor Haym por Munk em 1845, o Avicebron dos escolásticos não fôra identificado com o filósofo judeu Schlomo ibn $\mathrm{Ga}$ birol (c. 1020-1058).

A importância de Gabirol na formação do pensamento latino não foi menor que a de Avicena ou, mais tarde que a de Averrois.

Para o historiador da filosofia medieval M. de Wulf, Avicebron é capital na formação da metafísica pretomista, chegando a usar a expressão "agostinismo avicebronisante" para designar certo matiz do pensamento latino. Seu tradutor latino, Domingos Gundisalvo (Gundissalinus), que o introduziu na escolástica sofreu diretamente a sua influência e com isto também serviu de veículo para a sua difusão no Ocidente. Segundo Gilson, Gundisalvo também é a primeira fonte para a introdução do que êle chama de "agostinísmo avicenisante", colocarido as posições de Avicena sob um nôvo sentido, cristão (61). E dêste toma emprestado sua teoria da abstração claramente platonisante, fundamentada numa concepção dos universais extremamente realista e na constituição hilemórfica dos corpos. A composição universal de tôdas as coisas de materia e forma é de ibn Gabirol e é dêste filósofo que Gundisalvo tirou tal conceito para incorporá-lo a escolástica. Também de ibn Gabirol é o conceito da "luz" como a primeira forma das coisas e que se repetirá em São Boaventura de modo tão acentuado.

A obra central de ibn Gabirol, Mekor Haym (Fons Vitae) foi escrita em um estilo pouco atraente, às vêzes mesmo tedioso (62), èm forma de diálogo entre mestre e discípulo. Se baseia no princípio

\footnotetext{
"de que tôdas as substâncias espirituais possuem uma forma espiritual; de que a forma vem de cima e a matéria é o substrato e a forma é montada sôbre ela" (63).
}

A maioria dos elementos encontrados no sistema de ibn Gabirol são oriúndos da tradição neoplatônica (64) e o próprio tradutor do

(61). - Gilson (E.), Les sources greco-árabes de l'augustisme avicennisant, in AHDLMA, t. IV, 1929-30, pp. 85-91.

(62). - Husik (I.), A history of mediaeval jewish philosophy. Meridian Books. Philadelphia. 1960, p. 63.

(63). - Munk (S.), Melanges de philosophie juive et arabe, Libreirie Philosophique J. Vrin, Paris, 1955. No texto hebráico, na parte final da obra de Munk:

(64). - Guttmann (Julius), Phiiosophies of Judaism. Anchor Book. New York. p. 102: "most of the elements from which Gabirol's system is constructed are derived from the Neoplatonist tradition, and even where this does not appear to be the case, we must suspect lacunae in our knowledge of the Neoplatonic sources".

"V' ze' hasefer banui al ki iesh l'chol haatzamim haruchaniim iesod ruchani v'hatzura tavo memaala vehaiesod mekabel ota m'lmata kelomar she haiesod munach v'hatzura n'sua alav". 
texto ao hebráico, Shem-Tov ibn Falaquera diz que o autor se baseia no livro de Empedocles (pseudo), um dos muitos livros que circulavam na Idade Média em nome de autores da antiguidade tais como os importantes trabalhos de caráter neoplatônico, como a Teologia de Aristóteles e o Liber de Causis, o De anima, e outros (65).

Passamos a um resumo do conteúdo do Fons Vitae em seus cinco livros ou tratados: o primeiro livro contém as primeiras definições sôbre o que se deve entender como matéria e forma em geral. O autor fala das diversas espécies de matéria e forma, bem como da matéria e da forma universal. O segundo livro trata especificamente da matéria revestida da forma corporal (e a qual são aplicáveis tôdas as categorias), ou na linguagem do próprio autor, da substância levando a corporeidade do mundo. $O$ terceiro livro estabelece a existência de substâncias simples intermediárias entre o agente ou o eficiente primeiro, isto é Deus, e o mundo da corporeidade. No quarto livro se demonstra que estas substâncias simples são compostas de matéria e forma. E por fim o quinto livro trata da matéria universal e da forma universal, isto é das idéias de matéria e forma no sentido mais geral, e aplicados também tanto às simples, bem como às compostas. $O$ autor trata também da Vontade, primeira hipostase da divindade e que paira sôbre tudo que existe, sôbre as substâncias simples e compostas, sendo a fonte da qual emanam tôdas as formas (66) . O pensamento de ibn Gabirol chegará até a escola franciscana (67) na forma de conceitos saídos do Fons Vitae, desde o exemplarismo divino, a tendência de identificar o sêr e a luz, hilemorfismo universal, pluralísmo das formas substanciais (famossissimum binarium augustinianum), voluntarísmo, etc. . Em Duns Scotus, o último dos grandes filósofos da escola franciscana, o impacto das doutrinas do Avicebron não foi menor que ao dos outros acima mencionados. E no tocante ao papel da matéria afirma ser una para todos os sêres:

"Eu sustento que tôda substância criada, corporal ou espiritual, participa da matéria. E provo em seguida que esta matéria é una em tudo, quod sit unica materia" (68).

Adotando esta posição Duns Scotus se identifica plenamente com o pensamento fundamental de ibn Gabirol, não escondendo o filósofo franciscano a sua fonte

(65). - V. Fraile (G.), op. cit., pp. 668-674.

(66). - Munk (S.), op. cit., pp. 173-174.

(67). - V. Knowles (D.), The religious orders in England. Cambridge. 1950, p. 227, falando de João Pecham: "Jewish philosophy had left a legacy in its doctrine that spiritual substances were composed of matter and form, while to the body, considered apart from the soul, a forma corporeitatis was attributed".

(68). - Munk, op. cit., p. 298. 
ego autem ad positionem Avicembronis redeo.

c). - A influência da Espiritualidade Franciscana.

O espírito da Ordem fundada por S־o Francisco de Assis, levava a que seus filósofos ou teólogos ou ainda seus magistri, se identificassem com a linha de pensamento agostiniano.

A doutrina franciscana, se nos é permitido usar o têrmo doutrina, por falta de têrmo melhor, casava com a filosofia tradicionalista da Igreja, durante tôda a Idade Média, dominante até o século XIII. Tal doutrina apelava menos a "razão divina" e acentuava mais a "vontade divina", achegando-se ìntimamente a contemplação mística franciscana, vivida pelo fundador da Ordem pessoalmente e pelos seus primeiros seguidores e discípulos. Espiritualidade agostiniana e espiritualidade franciscana se aproximavam no desejo ardoroso de identificação com Deus, com o divino e sua criação. As páginas das. "Confissões" de Santo Agostinho muitas vêzes se assemelham à subida do monte Alvérnia. Há um paralelo no caminho das duas almas a Deus.

A exaltaçã̃o da natureza como divina por ser criação de um único sêr se manifesta nas laudas de São Francisco (69), bem como em determinados escritos de Santo Agostinho (70). Como diz E. Gilson, esta concepção do Cristianismo encerra um otimismo alentador em relação à natureza e à criação que decaiu mas que com a graça divina pode ser reparada (71) (redimida). Está implicado nesta posição um estado de alma próprio do pensamento franciscano em suas origens. Sendo assim, não é de estranhar que se por um lado o franciscanismo levava a contemplação mística, seguindo as pegadas de Sarto Agostinho, de outro lado podia levar a uma observação empírica da natureza, do tipo manifesto em Roberto Grosseteste e Rogério Bacon, manifestando um experimentalismo antecipado ao moderno

(69). - O "Laudes creaturarum" de São Francsico é o exemplo mais marcante. Fizemos referência a êste aspecto do franciscanismo em artigo publicado na Revista de História, $\mathrm{n}^{\circ} 70$, vol. XXXIV, 1967, p. 456.

(70). - Vejamos, como exemplo, ao explicar a origem do mal como a corrupção do modo da belcza e da ordem (modus, species et ordo) naturais, afirma que tudo é criação do sumo Bem, isto é, Deus, porque de "Deus receberam a existência e a bondade, por mais prquena e insignificante que esta seja". (De nat. boni, cap. VIIII). Também "tôdas as naturezas corruptíveis são naturezas, pois receberam de Deus o seu sêr..." e são corruptíveis porque foram criadas do nada. ( $D e$ nat. boni, cap. X).

(71). - Gilson (E.), L'Esprit de la philosophie mediévale. Librerie phil. J. Vrin. Paris. 1944, p. 132. 
(72), sem que com isto caia em contradição. O franciscanismo favorecia os dois caminhos em direç̃̃o a divindade: o ascendente, isto é, das criaturas ao Criador; o descendente, isto é, do Criador às criaturas. Quando os franciscanos ingressaram no caminho dos estudos encontraram uma formulação filosófica que refletia êste estado de alma, mencionado no estudo de E. Gilson, sôbre São Bcaventura (73), tratando-se da doutrina "das duas faces da alma". cujas origens remontam a fontes que antecederam o início da escola (74).

Apesar de tudo, o franciscanismo, de acôrdo com seu fundador, era anti-intelectualista e não se preocupou com construções filosóficas ou teológicas, rejeitando mesmo tôda a tendência que implicasse em estudos universitários e sistemáticos. A simplicidade dos Menores, segundo à formulação de seu fundador, era mais importante do que a ciência no caminho que levava à divindade (75). A imitação de

(72). - Genicot (L.), Le XIIIe siècle européen. Nouvelle Clio. Paris: 1958, p. 226. "En combinant expérimcntation, raisonnement et mathématiques, ces hommes jettent probablement les fondations de la science moderne et les bases de la supériorité future de la civilization occidentale".

(73). - Gilson (E.), La philosophie de Saint Bonaventure. Paris Librerie J. Vrin 1943, pp. 363-364. "Aux deus attitudes initiales entre lesquelles une âme raisonnable telle que l'âme humaine peut toujours opter: se tourner vers le haut, se tourner vers le bas. Problème fondamental, qui c'est pose pour l'humanité tout entière dans la personne du premier homme et qui continue de se pos:r pour chacun de nous lorsque nous déterminons la nature des objets qu'il nous convient de connaître. Ce problème, on le remarquera, ne concerne d'ailleurs pas exclusivement notre faculté de connaître, mais bien l'âme raisonnable tout entière, avec ses deux facultés de connaitre et de vouloir (g. n.). C'est l'âme qui se tourne vers le haut ou se laisse courber vers le bas, et, en se redressant ou en s'inclinant elle redresse ou incline son pouvoir de connaître. C'est porquoi la première distinction des officcs ou fonctions de la connaissance porte toujours chez saint Bonaventure le nom de l'âme plutôt que le nom de l'intellect; c'est la distinction de la raison supérieure et de la raison inférieure, c'est-à-dire de notre âme raisonnable considérée en tant qu'elle cherche au-dcssus ou au-dessous d'elle les objets qu'il lui convient de connaître ou d'aimer".

(74). - V. a respeito, Rohmer (J.), Sur la doctrine franciscaine des deux faces de l'âme, in "Archives d'histoire doctrinale et littéraire du moyen age", T. II, 1927, pp. 73-77. No artigo Rohmer cita a G. Bulow como rimontando a origem da doutrina ao De immortalitate animae de Dominicus Gundissalinus, que por sua vez teria à sua frente as fontes árabe de Algazel e a hebráica de Ibn Gebirol (o Fons Vitae); Rohmer acresce o De anima de Avicena, também como possível fonte da doutrina, mas destaca a incerteza existente na questão bem como a possivel e remota origem da expressão na fonte agostiniana e neoplatônica.

(75). - Há que separar em duas etapas ou fases a posição franciscana quanto aos estudos universitários: a). — a posição de seu fundador e primeiros seguidores, que os negavam, bem como formulavam um pensamento anti-intel-ctualista com base na humildade, a simplicidade e a negação de tôda propriedade e transporte de livros aos frades; esta posição durou pouco tempo e pràticamente poucos anos após a morte de seu fundador a realidade era outra, b). - a nova posição de admitir os estudos universitários, tanto a clérigos como a laicos, intensificando-se 
Cristo e seus Apóstolos não se coaduna com a ciência humana, que requer uma estabilidade que se afastava do apostolado a que se propôs a Ordem. Mas quando a Ordem adota os estudos universitários e se destaca nos centros de Paris e Oxford ela demonstrará um pensar, um filosofar e um teologisar próprio, muito aliado ao espírito regente, de seus ideais apostólicos (76). Se formulará, através de seus representantes e mestres, uma "doutrina" franciscana, com posições próprias e dominantes nas disputas filosóficas do século XIII, até que o impacto filosófico causado pelo surgimento das interpretações de São Tomás de Aquino, venha renovar a especulação filosófica e teológica, enriquecendo-a com os elementos novos saídos de Aristóteles.

E' importante observar que São Tomás não introduziu inteiramente conceitos aristotélicos no pensamento do século XIII, pois, ao bem da verdade, a escola franciscana se utilizava dos mesmos desde o início e mesmo Santo Agostinho não tinha deixado inteiramente Aristóteles de lado.

\section{d). - As escolas de Oxford e Paris.}

Com o desenvolvimento dos "estudos" na Ordem, passaram os Franciscanos a tomar uma parte ativa na vida Universitária da Europa.

As novas Ordens religiosas receberam em suas fileiras mestres universitários, aumentando o número de alunos que procuravam as studia dos mendicantes. A concorrência entre os religiosos e o clero secular, principalmente na Universidade de Paris, aumentou ao ponto de levar a um conflito aberto entre ambos, já que os mendicantes açambarcavam a maioria dos estudantes também do clero secular, constituindo portanto a base da cultura eclesiástica da época (77).

cada vez mais a penetração da Ordem nas Universidades (Bologna, Paris, Oxford). Esta questão a trataremos especialmente em nossa tese sôbre a Ordem Franciscana na Idade Média (em elaboração). Hilarino Felder, Los ideales de San Francisco de Assis, ed. Desclée, de Brouwer, Buenos Aires, 1948, cap. "San Francisco y la ciência", pp. 362-394, apesar de argumentar de que o fundador da ordem era a favor dos estudos, reconhcce a diferença das posições entre a primeira fase e a segunda.

(76). - São Boaventura caracteriza a ciência franciscana quando diferencia dominicanos e franciscanos do seguinte modo: "Os dominicanos se dedicam, principalmente, à especulação e depois à piedade; os franciscanos, principalmente, à piedade e depois à especulação. Oxalá, que esta piedade e esta unção nunca fiquem em segunda importância! (Alii principaliter intendunt speculationi et postea unctioni; alii principalit: $r$ unctioni et postea speculatoni. Et utinam iste amor vel unctio non recedat!", (Collatio XXII in "Hexaëmeron", n. 21).

(77). - Felder (H.), Los ideales de San Francisco de Assis, p. 378-379. O testemunho de Rogério Bacon, citado por H. Felder, na $o b$. cit., é muito esclarecedor: "Os clérigos scculares não compuseram nestes últimos quarenta anos nenhuma 
Até o século XIII não havia nas escolas do Ocidente lugar para o estudo da filosofia. Para quem se dedicasse aos estudos superiores de teologia, direito ou medicina, sòmente tinha que aprender a gramática ou seja, conhecer a língua latina e algo da lógica. Sòmente no século XII chegou ao conhecimento dos latinos a dialética de Aristóteles, e em princípios do século XIII, já começavam a se difundir as traduções da Física, da Metafísica e de obras sôbre ciências naturais, de Aristóteles. Mas a ciência cristã ou seja a teologia via como indigno aproveitar-se da filosofia grega para seu próprio uso. Havia o receio de que a filosofia de Aristóteles, ciência de um pagão, pudesse abalar a fé. Também as traduções árabes com os comentários próprios de Avicena e Averroes se mostravam perigosos ao Ocidente cristão. A Igreja, desde 1210, repetidamente proibiu a Facu'dade de Artes de Paris, a realizar cursos sôbre a física e a metafísica aristotélicas (78), até que fôssem depurados os erros contidos neles, servindo de recomendação que se expusesse a palavra divina seguindo aos Santos Padres em vez de recorrer aos filósofos pagãos, que não conheceram a Deus (79).

obra de teologia e estão convencidos de que não sabem nada se não estudarem dez ou mais anos com os individuos das duas Ordens. Não se atrevem tão pouco a ler as Sentenças nem graduar-se em teologia, nem ter uma lição ou disputa ou sermão, senão utilizando-se dos cadernos dos Frades mendicantes. E isto é claro a todos tanto na Universidade de Paris bem como em tôdas as partes". "Propter quod accidit, ut saeculares a quadraginta annis nullum composuerint in theologia tractatum, ncc reputant se aliquid posse scire, nisi per decem annos, vel amplius, audiant pueros duorem Ordinum. Nec aliter praesumunt legere sententias, nec incipere in theologia, nec unam lectionem, nec disputation $\mathrm{cm}$, nec praedicationem, nisi per quaternos puerorum in dictis Ordinibus; sicut manifestum est omnibus in studio $\mathbf{P a -}$ risiis et ubique" Rogeri Baconis, Compendium studii philosophiae, ed. Brewer, p. 426. Extratos dos textos Compendium studii philosophiae, também se encontra na $M . G . H .$, script., T. XXVIII, pp. 577-583. A citaçāo acima se encontra na p. 580 .

(78). - Os estatutos elaborados em 1215, para a orientação dos mestres, pelo legado papal Roberto de Courzon proibem expressamente a lkitura dos livros de física e metafísica de Aristóteles A proibição dos livros mencionados foi renovada por Gregório IX em 1231 com a ressalva "até que êles sejam examinados e purgados de tôda heresia". (V. Rashdall (H.), The Universities of Europe in the Middle Ages, Oxford University Press, 1951, vol. 1 pág. 357; Pelayo (M. M.), História de los Hetcrodoxos, B. A. C., Madrid, 1965, vol. 1, p. 428.

A expressão "Non legantur libri Aristóteles de methafisica" é explicada pelo verbo legere = ensinar, que nessa época consistia em se ler e comentar as Escrituras, Pedro Lombardo, Donato ou Prisciano. A proibiçāo da Metafísica que não era conhecida no fim do século XII nos círculos teológicos, era relacionada à Faculdade de Artes e principalmente a Medicina onde a Metafísica era conhecida e tinha portanto determinada influência. A propósito veja-se o interessante estudo de $\mathrm{Ch}$. Dickson, Le Cardinal Robert de Courson - Sa vie., in "Archives d'histoire doctrinale et littéraire du Moyen Age", T. IX, 1934, pp. 53-142.

(79). - Chart. Univers. Paris, ed. Denifle - Chatelain, I, $\mathrm{n}^{\circ} 11$, p. $70 \mathrm{n}^{\circ} 59$, pp. 114-116; n. 79, p. 138; n. 87, p. 143, cit. em Felder (H.), Los Idcales... pp. $388-389$. 
As Ordens religiosas, também foram advertidas contra o filosofia pag̃ , sendo que as antigas constituições dos dominicanos advertem:

'“Os Frades não estudem os filósofos pagãos; no máximo poderão dirigir uma rápida olhadela sôbre êles. Não aprendam ciência alguma mundana, a não ser que o mestre geral e o Capítulo geral queiram fazer uma exceção a algum ou outro religioso. Todos os demais, tanto jovens como anciöes, devem lêr sòmente livros teológicos" (80).

Porém superada a crise de aceitação, Aristóteles começou a ser aproveitado por meio de um trabalho seletivo em que afastados os erros e os comentários dos árabes que não se coadunavam com o pensamento cristão, passou a ser incorporado aos estudos universitários. E antes do que em outro lugar, isto ocorreu nas escolas franciscanas de Oxford e Paris.

Os primeiros franciscanos foram enviados por São Francisco à França, em 1219. Primeiramente viveram em uma casa de Saint-Denis. Em 1230 se estabeleceram em um grupo de casas de Paris, pertencentes a Saint Germain-des-Prés. Em 1234, São Luís comprou estas construções e uma área de terra e as ofereceu aos frades. Em 1236, Gregório IX confirmou-lhes a posse (81). Supõe-se que o fundador da escola franciscana em Paris, Alexandre de Hales, tenha ingressado na Ordem em 1235-1236, constando portanto como esta a data que dá início a Schola fratrum minorum.

Em primeira instância, a Escola seguiu o caminho do agostinismo, porém, adotando conceitos saídos da filosofia aristotélica e seus comentaristas árabes, opondo, todavia, uma doutrina filosófica própria ao peripatetismo árabe. Em relação ao problema do conhecimento, seu esfôrço é o de conciliar os dois pontos de vista diferentes; "a gênese empírica do conhecimento aristotélico" e a "visão agostiniana da iluminação de Deus", num trabalho de síntese bastante frutífero para o pensamento ocidental do século XIII. De acôrdo com Jean Rohmer, a "iluminação agostiniana" e a "abstração aristotélica" se farão concessões mútuas,

"dans lesquelles l'abstraction semble d'abord l'emporter sur l'illumination pour lui céder ensuite le pas" (82).

(80). - Die Konstitutionen des Predigerordens vom Jahre 1228, ed. Denifle, "Archiv für Litteratur und Kirchengeschichte". T. I, p. 222.

(81). - Feld:r (H.), Geschichte der wissenchaftlichen Studien im Franziskanerorden, Freiburg, 1904, pp. 168-74.

(82). - O problema é abordado em extenção, a começar por Alexandre de Hales, continuando em João de la Rochelle, São Boaventura, Mateus de Aquasparta 
Alexandre de Hales lançou os fundamentos da doutrina franciszana que, resumindo-a, poderíamos apontar os seguintes traços:

a) . - nenhuma distinção formal entre teologia e filosofia, ou seja a ordem da verdade racional e da verdade revelada;

b) . - primado da vontade sôbre a inteligência, da vida afetiva sôbre a intelectual;

c). - a necessidade de que alguns atos intelectivos no homem sejam provenientes de uma açã̃o iluminadora da parte de Deus;

d). - presença na matéria de princípios ou rationes seminales da coisa;

e). - hi'emorfismo universal;

f). - multiplicidade da forma no sêr contingente, principalmente no homem;

g). - individualização da alma por, virtude própria, especialmente no homem, e não como consequêencia da união com o corpo;

h). - identidade da alma com suas faculdades;

i). - impossibilidade da criação do mundo $a b$ aeterno (83).

Evidentemente, êstes traços característicos da doutrina variaram de um pensador a outro na própria Escola, tornando-se perigosa tôda generalização excessiva. Alexandre de Hales morrendo em 1245, deixou a Summa Theologica. que encerra a sua doutrina, considerada como sendo de autoria parte dêle e parte de seus discípulos. Sucedeu a Alexadre em Paris, em 1238 ou 1241, João de La Rochelle (Johannes de Rupella) autor de uma Summa de anima, que seguiu a linha estabelecida por seu antecessor.

Em Paris, a escola franciscana atinge seu ponto alto com São Boaventura, cujos traços gerais do seu pensamento mencionamos em capítulo anterior. Porém, outros se destacaram, como João Peckham

e termina com João Peckham. Neste estudo valioso Rohmer caracteriza a posição de cada um dêstes membros da Escola Franciscana, mostrando as nuances que diferenciam um de outro. São poucos os estudos de "síntese" que se pode encontrar sôbre a doutrina da Escola, exceto os trabalhos de J. Rohmer, E. Longpré, E. Gilson e outros poucos estudiosos. V. artigo de Rohmer, sob o título La theorie de l'abstraction dans l'école franciscaine d'Alexandre de Hales a.Jean Peckham, in "Archives d'histoire doctrinale et littéraire du Moyen Age", T. III, 1928, pp. 105-184 .

(83). - Enciclopédia Católica, vol. 1, 1949 verbete Alexandre de Hales. 
(c. 1225-1292) que lecionou em Paris, sob a orientação de São Boaventura, passando mais tarde a Oxford (84).

Em Oxford, os franciscanos estabeleceram-se em 1224 (85). Destacam-se em Oxford a figura pioneira de Roberto Grosseteste (c. 1168-1253) que foi magister scholarum (chanceler) da Universidade de Oxford e mais tarde Bispo de Lincoln. Foi homem versado em muitos campos, médico, advogado, pregador, Grosseteste teve interêsses orientados para às matemáticas e para à ciência física de um lado e do outro a teologia, a lógica e a metafísica. Traduziu do grego para o latim a Etica de Nicômaco e escreveu comentários a Analítica Posterior e a Phísica, escrevendo tratados sôbre astronomia e cosmologia, sôbre som, cometas, calor e outros fenômenos da natureza.

Seu discípulo e sucessor Rogério Bacon (c. 1224-1292) não deixou de revelar o mesmo espírito curioso de seu mestre, enveredando pelo caminho das ciências naturais, matemáticas bem como, pela especulação teológica e filosófica (86). Ligados à escola franciscana de Oxford estão os nomes de Adam Marsh, Tomás de York, Ricardo Rufus, Nicolas de Occam, Guilherme de la Mare, Rogério Marston, Mateus de Aquasparta e outros mais.

\section{e). - Polêmicas e controvérsias que a escola enfrentou.}

A vida universitária medieval nos dois grandes centros de Paris e Oxford, não foi desprovida de convulsões e polêmicas filosóficas que agitaram a Escola Franciscana levando-a a participar ativamente nestas contendas.

Sabemos que os mendicantes tiveram que enfrentar o clero secular nos inícios de sua vida universitária em Paris, despertando a inveja e a ira de muitos. Ao enfrentarem o clero secular, os mendicantes (franciscanos e dominicanos) estavam unidos em tôdas as fases da polêmica em questão, que no fundo girava em redor dos ideais das novas Ordens. Porém, ao passar à polêmica com os seculares, as antigas diferenças entre as duas Ordens surgiram à tona, sendo que a disputa filosófica revelava duas concepções antagônicas em sua base: a agostiniana de um lado e a aristotélica de outro.

(84). - V. Vogt O. F. M. (B.), Der ursprung und die Entwicklung der Franziskanerschule, in "Franziskanische studien", 1922, pp. 137-158. Também, E. Longpré, O. F. M., L'École franciscaine in la France Franciscaine, T. 'VI, 1923, pp. 108-134. Para o"Studium generale" de Paris é interessante consultar Glorieux (P.), Répertoire des maitres en théologie de Paris au XIIIe siècle, J. Vrin, Paris, 1933, V. I. pp. 5-243.

(85). - Little (A. G.), The Franciscan School at Oxford in the 13th century, in "Archivum Franciscanum Historicum", XIX (1926), pp. 803-74.

(86). - Rashdall, The Universities..., V. I, pp. 239-249. 
Os dominicanos, principalmente após o trabalho efetuado por Alberto, o Magno e São Tomás de Aquino, assumiram o papel de defensores da linha aristotélica (dentro da reformulação cristã elaborada por São Tomás).

Os franciscanos mantiveram nestas polêmicas a posição tradicionalista, ainda que não podemos falar que os dominicanos assumissem uma posição "progressista", já que o próprio uso dêstes têrmos não se aplica à questão ou questões em disputa .

Tanto em Paris quanto em Oxford a não aceitação de Aristóteles foi igualmente violenta!

Em Paris a polêmica anti-aristotélica têve, em certa fase, como fundo a imagem da heresia de Amaury de Bène e de David de Dinant, portanto sendo mais exacerbada nos seus ânimos. Porém, em Oxford, que não conheceu a heresia amalrisiana a polêmica teológica foi mais amena, ainda que ela se tenha realizado em extensão e profundidade.

Principalmente girava a polêmica ao redor de duas teses fundamentais: 1). - a composição hilemórfica de todo sêr criado tanto corpóreo quanto espiritual (materia universalis forma universalis), que permitia a distinção ontológica entre Deus e os sêres criados; 2). a pluralidade de formas substanciais em um mesmo indivíduo. A forma substancial sòmente lhe dava uma perfeição específica determinada, mas antes dela se sobrepunham na matéria prima outras diversas, especialmente a forma genérica de corporeidade (forma corporeitatis, forma cadavérica), que podia subexistir com independência da substancial e que permanecia na matéria ainda após a morte. Sendo assim, a tese da unidade da forma era considerada contrária a fé, uma vez que com ela dificilmente poder-se-ia explicar algumas verdades que eram partes dela, tais como a Encarnação, a Eucaristia, a Ressurreição dos corpos, etc. (87).

São Tomás negava tanto o hilemorfísmo universal, bem como sustentava a unidade da forma substancial e com tudo o que isto implicava. Ao começarem as polêmicas em 1267, no convento franciscano de Paris se destaca a figura de João Peckham, regente da mesma escola. A êle se ajuntaram também Gualter de Bruges e Guilherme de La Mare e em Oxford, o dominicano Roberto Kilwardby. Todos com posição idêntica frente ao tomismo.

Estas posições, que em seus traços gerais eram idênticas entre os teólogos da Ordem franciscana, se resumem na aceitação da divina iluminação do intelecto como parte de todo ato cognoscitivo perfeito;

(87) . - Fraile (G. O. P.), História de la Filosofia, II, B. A. C., Madrid, 1966, p. 1022. 
no hilomorfísmo, que inclui de um lado uma concepção de matéria que pode existir como algo aparte da forma e por outro a presença de matéria espiritual como parte da composição dos sêres espirituais; a identificação das faculdades da alma com sua essência; a existência simultânea de algumas formas animadas e de uma forma do corpo (forma corporeitatis) ao homem; a existência na matéria do que é dominado potência ativa (ratio seminales de Santo Agostinho) que assume uma ou mais formas particulares em lugar de outras (88). Nestas polêmicas, segundo Knowles, é possível distinguir as três posições caracterizadas: a primeira, pela tradicional escola franciscana que se inicia com Alexandre de Hales e se estende a Sâo Boaventura na qual se podem notar a existência de elementos tirados de Platão, Santo Agostinho, Aristóteles e seus comentadores árabes e judeus. Ressalvando-se que a escola de Paris era mais livre de elementos aristotélicos que as de Oxford. Esta seria uma posição extrema do lado tradicional tendo como extremo oposto a posição de Siger de Brabante e Boécio da Dácia que afirmaram o sistema peripatético e os comentários de Averroes e Avicena. A posição intermediária seria a representada pelos dominicanos Alberto, o Magno e Tomás de Aquino. Conforme G. Fraile (89) a tese da unidade da forma substancial de São Tomás coincidia com os aristotélicos heterodoxos, sendo que seus adversários se empenharam em envolvê-lo na condenação anti-averroista de 10 de dezembro de 1270.' Parece que o total das condenações apresentadas era de quinze, sendo que na última hora foram retiradas as duas últimas que estavam implicadas com a tese da unidade da forma substancial e a negação do hilemorfismo universal.

Da disputa tomista ou anti-tomista sabemos, através do Chartularium, que o princípio de individuação da matéria foi condenado pelo Bispo de Paris, Estevão Tempier, em 1277 (90), entre um grupo de teses averroistas. Estevão Tempier, foi convocado por João XXI, em 18 de janeiro de 1277 para que investigasse os erros que circulavam na Universidade de Paris. Convocando uma assembléia de mestres de Teologia, promulgou a condenação de 219 proposições averroistas bem como algumas, cêrca de vinte, que se identificavam como sendo posições de São Tomás. Quando morreu João XXI, em 20 de maio de 1277, os cardeais ordenaram a Tempier que se abstivesse de prosseguir naquele assunto $(91)$.

(88). - Knowles (M. D.), Some aspects of the career of Archbishop Pecham, in "The English Historical Review", vol. 57, Jan. 1942 pp. 1-18; 178-201.

(89). - Fraile, p. 1023.

(90). - 7-3-1277.

(91). - Fraile, p. 1024. 
Ao mesmo tempo que isto ocorria em Paris o arcebispo (dominicano) Roberto Kilwardby, no concílio de Oxford (92), condenou a doutrina tomista da "unidade da forma" no homem (quod vegetativa, sensitiva, et intellectiva sunt una forma simplex). A doutrina tomista era de que a anima rationalis é a única "forma" do homem e que desempenha nele as funções que as almas ou formas vegetativa ou sensitiva desempenham nos animais inferiores.

Parece que a condenação de Paris é fruto do bispo, sem, assim transparece, 0 apôio da Universidade, enquanto que $o$ arcebispo inglês expressa o consentimento dos mestres.

Ao dizer de Fraile, a posição de Kilwardby era um pouco mais benévola do que a de seu colega em Paris, ameaçando os adeptos das teses com graves penas, mas não os proibindo sob pena de excomunhão concedendo mesmo sessenta dias de indulgência aos que não os ensinassem. A preocupação teológica dos que condenavam a unidade da forma substancial estava ligada à questão da identidade do corpo de Cristo antes e depois da morte, razão suficiente e pela qual não se poderia apreciar a polêmica sob o aspecto puramente filosófico (93) . Porém com o passar do tempo as posições de São Tomás e sua elaboração filosófico-teológica foram se fixando na Ordem dominicana ao ponto de nos capítulos de Milão de 1278 e de Paris de 1279 resolverem favoràvelmente a defesa da doutrina do mestre (94) .

(92). $-18-3-1277$.

(93). - "Decimus quartus: quod corpus Christi iacens in sepulchro et positum in Cruce non est vel non fuit idem numero semper, sed secundum quid" - "Quindecimus: quod angelus et anima humana sunt simplices, sed non absoluta simplicitate, nec per acessum ad compositum, sed tantum per recessum a summo simplici" (apud Fraile p. 1023, P. Mandonnet, Siger de Brabant, p. 107).

(94). - Ehrle (F.), Beiträge zur Geschichte der mittelalterlichen Scholastik, in "Archiv für litteratur und kirchengeschichte das Mittclalters", V., p. 604-605; $O$ texto das resoluções constam como nota de rodapé das páginas citadas: "Der Beschluss des Mailänder Generalkapitels lautet: "Item iniungimus districte fratri Raimundo de Medullione et fratri Joanni. Vigorosi, quod cum festinatione vadant in Angliam, inquisituri diligenter super facto fratrum qui in scandalum ordinis de scriptis venerabilis fratris Thomae de Aquino obloquuntur. Quibus ex nunc plenam damus auctoritatem in capite et in membris. Qui quos culpabiles in venerint in praedictis punicndi, extra provinciam emittendi et officio privandi plenam habeant potestatem. Quod si unus eorum casu aliquo ligitimo fuerit impeditus, alter eorum nihilominus exsequatur. Quibus priores de sociis competentibus, quos ipsi ad hoc officium exsequendum idoneos iudicaverint, teneantur, quandocunque requisiti fuerint, providere".

"Das folgende Generalkapitel von Paris 1279 beschloss": Item venerabilis vir, recolendae mcmoriae frater Thomás de Aquino sua conversatione laudabili et scriptis suis multum honoraverit ordinem, nec sit aliqualiter tollerandum, quod de ipso vel scriptis suis aliqui irreverenter loquantur etiam aliter sentient:s; ideo iniungimus prioribus provincialibus et conventualibus ac eorum vicariis, et visitatoribus universis, quod si quos invenerint excedere in predictis, punire acriter non postponant". 
Ainda que a posição tradicional dentro da Ordem não deixasse de existir igualmente forte e representativa como antes Ehrle menciona os nomes de Rolando de Cremona, Roberto Fitzacker, Hugo de Saint Choir, Petrus de Tarantaria e Roberto Kilwardby, como os que se destacaram nessa posição (95).

Em 1284 João Peckham, da Ordem franciscana renovou com sua visitação, a condenação de 1277 .

As controvérsias porém não terminaram e em 1278 Guilherme de La Mare, publicará o Correctorium fratris Thomae que leva a Ricardo Klapwell (96) a escrever o seu Correctorium corruptorii como resposta da posição tomista a agostiniana de G. de La Mare. Em 1286, Klapwell foi condenado por João Peckham, terminando esta fase da polêmica entre tomistas e agostinianos, polêmica que implicava também como uma de suas consequiências o estabelecimento da Teologia, da doctrina sacra, como ciência sôbre bases novas, ou seja, sôbre o método aristotélico aplicado vigorosamente pela primeira vez por Tomás de Aquino na Suma Teologica (97).

\section{(Continua) .}

(95). - Ibidem, p. 605.

(96). - Chenu (M. D.), La première diffusion du thomisme à Oxford. Khapwell et ses "Notes" sur les sentences in "Archives d'histoire doctrinale et littéraire du Moyen Âge", T. III, 1928, pp. 185-200.

(97). - Chenu (M. D.), La Théologie comme science au XIIIe siècle, in "Archives d'histoire doctrinale et litteraire du Moyen Áge", T. II, 1927, pp. 31-72. 